\title{
Uma abordagem sistêmica da atual crise ambiental
}

\section{A systemic approach of present environmental crises}

\author{
Eduardo L. KRÜGER
}

\section{RESUMO}

\begin{abstract}
Neste artigo, é traçado inicialmente um quadro histórico acerca do surgimento da sociedade tecnológica. Em seguida, aponta-se para alguns problemas criados por essa sociedade, à luz do conflito existente entre os avanços tecnológicos e os prejuízos causados ao meio ambiente. As seções seguintes discutem o enfoque ambientalista e a abordagem sistêmica para essa questão, para que se possa, por fim, esboçar algumas estratégias no sentido de propor melhorias para o sistema global.
\end{abstract}

Palavras-chave: tecnologia, ambientalismo, teoria geral de sistemas

\begin{abstract}
In this article, we first present a brief historical picture from the beginnings of the technological society. Then, we point out some problems created by this society in the light of the existing conflict between technological progress and the damages brought to the environment. The following sections discuss the environmentalist vision and the systemic approach to this issue, in order to outline some strategies to improve the global system.
\end{abstract}

Key-words: technology, environmentalism, general systems theory

\section{O surgimento da sociedade tecnológica}

A técnica, nas sociedades primitivas, sempre esteve associada ao artesanato e à produção de utensílios necessários à subsistência e à proteção de indivíduos e coletividades humanas. Alguns autores relacionam inclusive a produção da pedra lascada ao aparecimento do Homem, como fatos simultâneos (VARGAS, 1994). Apesar disso, a tecnologia não é um conjunto de técnicas ou de todas as técnicas e nem é a sofisticação da técnica. A passagem da técnica para a tecnologia não é questão de gradação ou desenvolvimento interno ao campo das técnicas, refere-se antes à condição socioeconômica em que a tecnologia está inserida. Mais ainda, o que distingue a tecnologia da técnica é a sua fundamentação científica.

Em um estágio inicial, a Natureza domina o Homem. Entre 50 e 40 mil anos atrás, caçadores e coletores apresentavam técnicas rudimentares, tendo o nomadismo sem acumulação de bens como principal modo de vida. A organização tanto das pequenas comunidades como do tempo era primitiva. Com o surgimento da agricultura (10 mil anos 
atrás), houve o domínio das técnicas por todos os membros da comunidade. O modo de vida tornou-se sedentário, havendo o aparecimento de regras, chefias, com organização política e temporal marcada por períodos de plantio e colheita. A era do ferro fundido (3 a 4 mil anos atrás) marcou o início da especialização do trabalho com uma estratificação da sociedade e do conhecimento e uma conseqüente perda individual do domínio do conhecimento.

Só a partir do século XVII, com o surgimento da ciência moderna, é que apareceu a tecnologia como é entendida hoje em dia; isto é, um saber fazer baseado em teoria e experimentação científica, não sendo possível separar nitidamente as duas. Com a Revolução Industrial do século XVIII, deu-se a aliança entre ciência e técnica. A despeito de alguns analistas do episódio assinalarem com ênfase a não-participação da ciência na Revolução Industrial, essa não-contribuição se refere à ação científica direta. Indiretamente, a ciência teve uma presença marcante, sobretudo através do método e do espírito científico no meio técnico e artesanal. O ideal da ciência se disseminou entre os artesãos manufatureiros, mormente no Norte da Inglaterra (MOTOYAMA, 1995). A reunião da técnica com a disciplina científica atinge um alto nível de generalidade e de sistematização, quando se desenvolvem processos próprios de trabalho, apresentando uma grande importância para alguns intelectuais franceses contemporâneos, que nela vêem exatamente a transição da técnica para a tecnologia (GAMA, 1986).

Assim, no século XIX, verificou-se o aparecimento das primeiras sociedades tecnológicas. Com os Estados Unidos à frente na corrida tecnológica, deu-se uma dinamização do meio técnico e científico em grande parte das economias mundiais (MOTOYAMA, 1995). Neste quadro, ocorreu a segunda Revolução Industrial: o automatismo. Enquanto a primeira Revolução Industrial, situada entre o final do século XVIII e o início do século XIX, teve o grande mérito de substituir o esforço físico do Homem pela energia das máquinas (inicialmente através da utilização do vapor e mais adiante sobretudo pela utilização da eletricidade), a segunda Revolução consistiu na substituição do Homem por autômatos, que eliminaram com êxito o trabalho humano na produção, tornando possível a ampliação de suas capacidades intelectuais (SCHAFF, 1995).

Mas o fator tecnológico provoca profundas alterações na vida social, econômica, política e ambiental. Os produtos e processos envelhecem mais cedo e são rapidamente substituídos. A competição cresce e os mercados se ampli- am, configurando o fenômeno conhecido como globalização. Paira o perigo do tecnopólio: a submissão de todas as formas de vida cultural à soberania da técnica e da tecnologia (POSTMAN, 1994). Verifica-se uma "reificação da tecnologia", onde o conhecimento tecnológico permite que haja o domínio sobre sociedades dependentes de tecnologia, atuando como fator de poder, havendo uma clara divisão entre países dominadores de tecnologia e países consumidores de tecnologia (CARVALHO, 1997).

\section{A sociedade tecnológica e a perda do domínio do homem sobre os avanços tecnológicos}

Tecnologias de grande-escala presumem a existência de grandes organizações e complexos industriais, com uma movimentação de elevados volumes de recursos materiais e energéticos. Isso significa uma especialização cada vez maior do trabalho e a desvalorização do mesmo. O trabalho produtivo, executado pelo trabalhador, passa a ser executado por máquinas e a ação humana passa a ser desprestigiada. A necessária concentração de pessoas em núcleos urbanos tem como conseqüências o individualismo, o aumento da criminalidade, a decadência dos valores tradicionais. O manejo de grandes volumes de materiais e energéticos está diretamente relacionado à geração de detritos e poluentes, à degradação do meio, dentre outros fatores.

Algumas características do complexo tecnológicoindustrial são: a irreversibilidade da introdução de novas tecnologias, a rapidez e a abundância com que inovações e novos produtos são introduzidos no mercado e a imprevisibilidade dos efeitos de sua aplicação, o que conduz a uma impossibilidade de haver uma avaliação criteriosa das reais conseqüências da aplicação de inovações tecnológicas. A lei de Moore, assim chamada em razão das previsões do co-fundador da Intel, Gordon Moore, que profetizou que o número de circuitos em um chip duplicar-se-ia a cada ano, retrata uma aceleração progressiva e inexorável observada em computadores, na biotecnologia, na nanotecnologia, dentre outras. Essas novas invenções se diferenciam das mais antigas como os automóveis, os televisores e os aviões a jato, que aceleraram inicialmente, para depois progredirem de modo gerenciável, estável e previsível, sendo acompanhadas de um processo de maturação. As atuais tecnologias que se auto-aceleram, como no caso de computadores, onde os produtos gerados 
por seus próprios processos as permitem progredir ainda mais rapidamente, geram condições de instabilidade e imprevisibilidade (BRAND, 2000). Torna-se difícil controlar esse avanço, pois, se um país limita o seu avanço tecnológico, algum outro o assume. Segundo Brand, revoluções tecnológicas constantes tornam qualquer planejamento complicado e a falta de planejamento conduz a sociedades frágeis.

O entomologista e curador do Smithsonian Institute Terry Erwin, citado em NAISBITT (2000), adverte sobre o perigo de um processo de extinção em massa em nosso planeta, que, diferentemente dos anteriores (era glacial, as grandes inundações e os impactos causados pela queda de asteróides), de certa forma locais, ocorreria de forma global e na atmosfera, o assim chamado sexto processo de extinção das espécies. A menos que anticipemos e possamos atenuar o impacto de novas tecnologias, antes de sua aplicação, será impossível que façamos uso das mesmas de modo pensado e eficaz, assegurando a sobrevivência de nossa espécie. Observando-se, por um lado, alguns princípios básicos do uso da tecnologia de grande-escala, verifica-se que, enquanto na Natureza há limites, tendo em vista a manutenção do necessário equilíbrio, na tecnologia de grande-porte não se reconhece a existência de quaisquer limites, não podendo portanto haver equilíbrio. Assim, a tecnologia de grande-escala contém uma contradição a um princípio básico da Natureza, sendo gerada aí uma oposição entre Natureza e Tecnologia.

Além disso, o objetivo primordial da tecnologia, que é o de aliviar o Homem da tarefa de sobreviver, possibilitando um maior desenvolvimento de seus potenciais, significa a longo prazo uma dependência da máquina. Essa perda gradual da autonomia e do domínio do Homem sobre seus inventos indicando um aparente domínio da tecnologia pode ser bem observada no exemplo do automóvel.

A criação do primeiro automóvel foi saudada devido à grande utilidade entrevista neste invento. Não apenas tornou-se possível percorrer maiores distâncias que as percorridas a pé ou em carroças puxadas por tração animal, mas também passou a haver maior tempo disponível para que as pessoas "desenvolvessem seus potenciais". A partir dessa nova invenção, cidades se desenvolveram em função das novas possibilidades de locomoção humana: o que antes era feito a pé, hoje só é possível através de automóveis. O que deveria promover maior liberdade ao Homem, tornouo dependente, gerou stress e não significou necessariamente uma economia de tempo, lembrando da situação antes da introdução daquela tecnologia, com comunidades pequenas desenvolvendo atividades dentro de pequenas distâncias. Isso sem mencionar ainda os danos ambientais relacionados à queima de combustíveis fósseis. Entretanto, não se pode ser simplista a ponto de negar as características positivas da introdução do automóvel na vida humana, como o aumento da mobilidade, a facilidade no transporte de cargas, além das vantagens socioeconômicas relacionadas à indústria automobilística de um modo geral.

\section{O discurso ambientalista}

Os primórdios do movimento ambientalista confundem-se com as primeiras discussões engendradas pelo Clube de Roma na década de 60 (ODUM, 1988). Criado em 1968 pelo empresário Aurelio Peccei, o chamado Clube de Roma reunia cientistas, pedagogos, economistas, humanistas, industriais e funcionários públicos, com o objetivo de debater a crise atual e futura da humanidade.

O primeiro relatório elaborado pelo Clube de Roma (Limits to Growth, de 1972) causou enorme impacto entre a comunidade científica, por apresentar cenários catastrofistas de como seria o planeta, caso persistisse o padrão de desenvolvimento vigente na época. A partir daí, outros relatórios alertavam com freqüência para a necessidade de se mudar o padrão de desenvolvimento vigente. Pode-se citar também o 2. ${ }^{\circ}$ Relatório do Clube de Roma (Mankind at Turning Point, de 1974), editado por Mihajlo Mesarovic e Eduard Pestel, que identifica dois desníveis em nosso planeta: entre o desenvolvimento humano e a Natureza e entre ricos e pobres, propondo desenvolvimentos diferenciados, específicos para cada região, nos quais se reconhecem as diversidades existentes. Think global, act local, essa era a mensagem deste relatório. O 3. ${ }^{\circ}$ Relatório (RIO: Reshaping the International Order, de 1977), coordenado pelo economista Jan Tinbergen, propunha a consolidação de metas locais com metas globais para garantir o bem da humanidade como um todo.

Interessante observar que, à medida em que iam sendo discutidos temas relacionados ao meio ambiente, acontecimentos noticiados pela grande imprensa faziam ver a veracidade dos fatos apresentados nos relatórios e a complexificação das inter-relações no ecossistema terrestre devido ao padrão de desenvolvimento adotado. Assim, surgiram, em 1973/1974 e 1979/1980, duas ondas sucessi- 
vas de elevação dos preços do petróleo no mercado internacional, abalando essa fonte energética que fora, até então, um dos principais alicerces da sociedade industrial (LA ROVERE, 1985). Por toda parte, verificam-se acidentes relacionados ao uso de fontes de energia não-renováveis, como os acidentes nucleares de Three Mile Island, em 1979, e de Chernobyl, em 1986, este último com um débito de cerca de 2500 vidas humanas, a tragédia ambiental causada pelo vazamento do petroleiro Exxon Valdez, em 1989, dentre outros. A falta de controle também se verifica no caso de incidentes envolvendo desmatamentos, como, por exemplo, na bacia de Yangtze, na China, onde inundações causaram a morte de 3700 pessoas, atingindo 24 milhões de hectares de área de plantio. Desse tipo de impacto de grande-escala no meio ambiente surge o termo eco-migrantes: migrações em massa a partir de áreas degradadas.

No entanto, o movimento ambientalista, em vista dos impactos em escala planetária de um uso exacerbado da tecnologia, acaba esbarrando em entraves políticos. Toda vez que o princípio de autodeterminação dos povos é ferido, ações políticas são postas em prática, que contradizem resoluções discutidas em consenso. Por exemplo, pode-se citar a atitude de alguns países em relação às resoluções do Protocolo de Kyoto. De acordo com este Protocolo, assinado em 97, mas ainda não ratificado, os países industrializados deverão, até 2012, reduzir em média 5\% das emis- sões de gases-estufa lançados na atmosfera, em relação aos níveis da década de 90 . O impasse surge quando o principal país poluidor, os Estados Unidos da América, com uma emissão anual de dióxido de carbono $\left(\mathrm{CO}_{2}\right)$ de 186.1 bilhões de toneladas (World Ressources, 2000-2001), em razão de uma crise econômica interna, se nega a cumprir o anteriormente acordado, sobrepondo interesses nacionais a uma realidade global de perspectivas pessimistas.

\section{A questão dos limites e a abordagem sistêmica}

As inúmeras implicações socioeconômicas e ambientais associadas ao desenvolvimento tecnológico, da forma como é conhecido, fazem refletir sobre a questão dos limites. O discurso ambientalista vem forçando cada vez mais a adequação do desenvolvimento socioeconômico a padrões estabelecidos (certificações ambientais do tipo ISO 14000, selo verde etc.), relacionados à capacidade de regeneração dos ecossistemas. No entanto, há que se repensar a introdução, o desenvolvimento e a aplicação de novas tecnologias, não restringindo a análise tão somente aos seus efeitos.

A seguir, são apresentadas algumas curvas tendenciais relativas a um setor que parece extremamente problemático quanto às suas implicações socioambientais:

\section{FIGURA 1 - FROTA DE AUTOMOTIVOS E SUAS IMPLICAÇÕES NUM} HORIZONTE GLOBAL

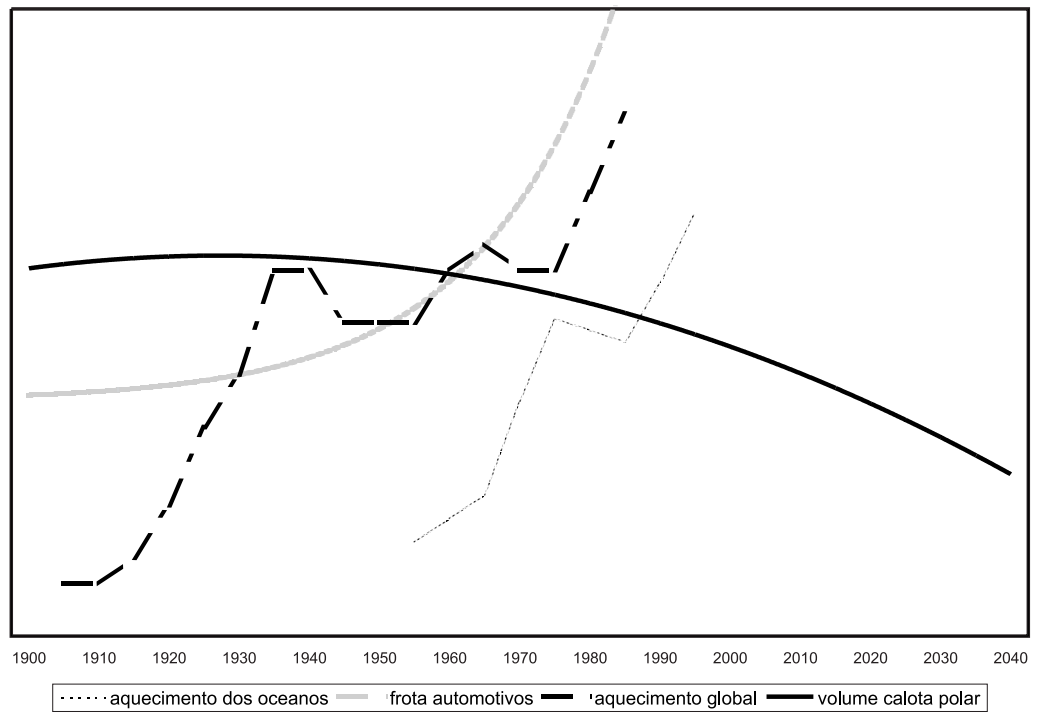


a indústria automotiva. À moda do primeiro relatório de impacto do Clube de Roma (MEADOWS, 1978), foram suprimidas propositalmente as escalas das ordenadas e adotadas curvas de tendência para que se tenha um quadro geral da situação.

Num horizonte global (figura 1), o crescimento da frota de automotivos (automóveis e caminhões) dá-se em ritmo acelerado (baseado em GOLDEMBERG, 1996), aparentemente alheio às implicações ambientais do aquecimento global da atmosfera (GOLDEMBERG, 1996) e da temperatura dos oceanos (BARNETT, et al., 2001), gerados em grande parte pelo uso generalizado de combustíveis fósseis e do consequiente derretimento da calo- ta polar (KONSTANTIN, et al., 1999). Se, há dez anos, a comprovação de que o aquecimento do clima global tem origem antropogênica ainda era passível de críticas, desde 1995 verifica-se um decréscimo substancial nas incertezas. Segundo recente relatório do Intergovernmental Panel on Global Climate, financiado pelas Nações Unidas, a temperatura média da Terra em 2100 poderá sofrer um acréscimo de até $5.8^{\circ} \mathrm{C}$ (KERR, 2001). Modelos climáticos, como os de Barnett et al. (2001), onde são simuladas situações de aquecimento dos ocea$\operatorname{nos}^{1}$ devido à emissão de gases antropogênicos, têm mostrado boa correspondência com dados provenientes de medições, o que reforça a precisão dessas estimativas.

\section{FIGURA 2 - FROTA DE AUTOMOTIVOS E SUAS IMPLICAÇÕES NUM} HORIZONTE NACIONAL

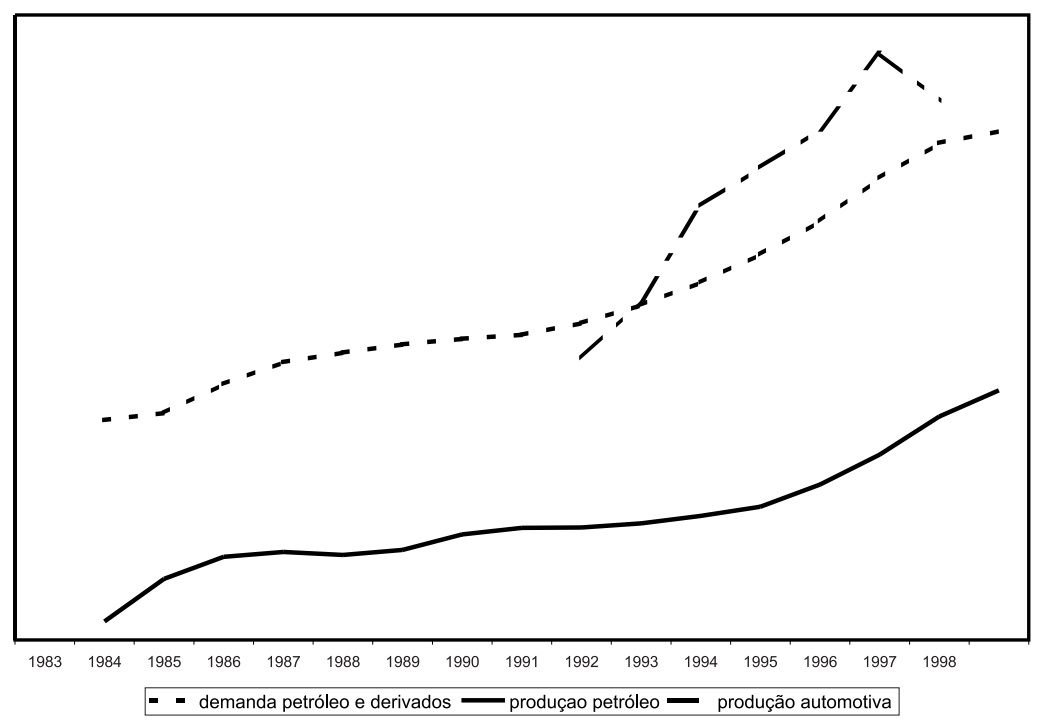

No caso brasileiro (figura 2), analisando a tendência da mesma indústria (automotiva), verifica-se que o seu crescimento (dados da Anfavea para 1998, disponível em: http://www.ppga.ufrgs.br/crs/diagnostico/nacional02.htm [capturado em julho 2000]) parece não levar em conta o necessário aumento da produção interna de petróleo (MME, 1999), em grande parte ainda bastante dependente de importações externas (curva de tendência: demanda de petróleo e derivados).
Nota-se, a partir dos dois gráficos apresentados, a desconsideração por parte do complexo tecnológico-industrial da existência de limites naturais, sejam os relacionados à capacidade da biosfera de absorção dos gases gerados pelo Homem, sejam os relacionados à prospecção de um recurso natural esgotável e, o que é ainda mais agravante, criando dependência externa.

A noção de sistemas no âmbito de uma Teoria Geral de Sistemas surgiu na primeira metade do século XX, com

$1 \mathrm{O}$ aquecimento dos oceanos é preocupante, considerando a sua influência no clima global. Os oceanos constituem cerca de $72 \%$ da superfície do planeta, amenizando as variações diárias e sazonais com sua grande inércia térmica. 
os trabalhos de Köhler (1924), sobre a aplicação dos princípios da Gestalt na Física, Lotka (1925), na Estatística, definindo o conceito geral de sistemas e Von Bertalanffy, que propôs uma Teoria Geral de Sistemas de aplicação em diversas áreas do conhecimento, em especial na Biologia (Von BERTALANFFY, 1973).

Na hierarquia de sistemas, proposta por Ludwig von Bertalanffy (1968) e por Kenneth Boulding (1956), distinguem-se sistemas dos mais simples aos mais complexos, sendo feita uma distinção básica entre sistemas fechados e abertos, os primeiros considerados isoladamente de seu entorno (em experimentos da física convencional, por exemplo) e os últimos permitindo relações de troca entre o sistema e o meio. A Cibernética (WIENER, 1948) propõe que, para um sistema se manter estável, seja ele fechado ou aberto, é necessária a existência de mecanismos de controle. No primeiro caso, essa regulação se faz por um agente externo como, por exemplo, na manutenção de um ambiente a uma temperatura constante, através de um termostato. No segundo caso, ela se dá através de mecanismos retroativos, da auto-regulação.

Ervin Laszlo (1974), ao discutir sistemas socioculturais, aponta para a semelhança destes com sistemas naturais, orgânicos e, portanto, abertos. Grupos sociais se formam a partir das primeiras associações de indivíduos, nos quais a adaptação ao meio externo se processa através de mecanismos puramente biológicos. Quando o Homem primitivo passa a utilizar ferramentas, os mecanismos aos quais lança mão para promover sua adaptação ao meio, situados anteriormente no plano genético, são substituídos por um modelo de adaptação cultural, onde a habilidade de criar e usar ferramentas, gerar e transmitir conhecimento, aumenta a sua capacidade de controle sobre o meio ambiente. A partir dessa evolução, grupos humanos dão lugar a vilarejos, que, quando multiplicados, compõem sistemas maiores, havendo a formação inicialmente de impérios e, finalmente, de estados-nações, caracterizando uma evolução de sistemas socioculturais (LASZLO, 1974). Sendo sistemas socioculturais sistemas vivos, compostos de grupos humanos em permanente processo de mutação, devem apresentar caráter evolutivo, adaptando-se e ajustando-se ao meio igualmente em mutação.

A Cibernética nos ensina alguns princípios em se tratando de sistemas vivos, dentre os quais chama-se a atenção para o princípio de dimensão ótima de um sistema (VESTER, 1984). Neste sentido, a Biologia também aponta para a necessidade de se respeitar a capacidade de regeneração de ecossistemas (ODUM, 1988). Assim, a desconsideração de limites pelo Homem, enquanto componente do maior sistema existente no planeta, a Biosfera, torna-se, do ponto de vista sistêmico, ameaçadora para a estabilidade do sistema global e para que este não entre em colapso.

\section{Novos rumos}

Considerando a natureza evolutiva do pensamento ocidental, fruto de um dinamismo fortemente acentuado com as contribuições de Darwin na Biologia, em oposição às conclusões dos teóricos da Termodinâmica, que profetizavam uma morte cósmica do Universo com uma degradação por completo da energia existente, verifica-se ao longo da História a existência de uma evolução em sistemas socioculturais, apontando para um possível avanço para um próximo degrau evolutivo: a instituição de um sistema único de estados-nações, ou seja, a formação de um sistema global (LASZLO, 1974).

Assim, tendo em vista a manutenção do sistema global, como em qualquer outro sistema, seja ele natural ou artificial, deveria ser assegurada sua estabilidade. Para tanto, seria necessária a instauração de um mecanismo de homeostase global, que pudesse atuar de fato como agente regulador do sistema sociocultural, este não mais visto como um agregado de estados-nações, mas sim como um sistema único, composto por todos os integrantes do maior sistema existente no planeta: a Biosfera. Neste particular, a comprovação da ineficácia dos tratados internacionais quanto à aplicação de suas resoluções foi recentemente verificada na não-ratificação do Protocolo de Kyoto.

Um mecanismo homeostático global, como todo sistema cibernético, se baseia em: sensores, transmissores de informação e mecanismo regulador. Desta forma, há, inicialmente, a necessidade de haver um monitoramento constante das variáveis-chave para a sustentação do sistema, que Laszlo (1974) indica como sendo: ecologia, população, economia e segurança global. Em seguida, há que se considerar o importante aspecto da difusão de informações relativas à manutenção do sistema como um todo. Sobre esse aspecto, ou seja, o de levar a informação científica para o grande público, Norman Augustine (1998) ressalta dois pontos que merecem ser considerados: a necessidade de haver uma alfabetização científica (scientific literacy) da população e de uma comunicação eficaz de assuntos científicos a partir de cientistas. Por fim, o mecanismo regulador do 
KRÜGER, E. L. Uma abordagem sistêmica da atual crise ambiental

sistema global deverá proporcionar as melhores soluções humanas e tecnológicas disponíveis.

A natureza dos problemas ambientais nos tem mostrado que estes não se restringem apenas a localidades específicas nem se manifestam linearmente em relações de causa e efeito onde os agentes causadores do impacto são perfeitamente reconhecíveis. Considerando o impacto das tecnologias atuais, sua característica global aponta para a necessidade de um controle global. Há que se transcender a esfera dos estados-nações, configurando-se um grêmio de indivíduos comprometidos com a manutenção do sistema global e com a satisfação das necessidades humanas genuínas.

\section{REFERÊNCIAS}

AUGUSTINE, N. What we don't know does hurt us. How scientific illiteracy hobbles society. Science, Washington, v. 279, p. 1640-1641, mar. 1998.

BARNETT, T. P. et al. Detection of anthropogenic climate change in the world's oceans. Science, Washington, v. 292, p. 270-274, abr. 2001.

BOULDING, K. General systems theory: the skeleton of a science. Management Science, n. 2, p. 197-208, 1956.

BRAND, S. Is technology moving too fast? Time, New York, v. 155, n. 25, p. 70-71, jun. 2000. Visions 21 special issue: The Future of Technology.

CARVALHO, M. G. Tecnologia, desenvolvimento social e desenvolvimento tecnológico. Revista Educação \& Tecnologia, Curitiba, n. 1, p. 98-106, jul. 1997.

GAMA, R. A tecnologia e o trabalho na história. São Paulo: Edusp, 1986.

GOLDEMBERG, J. Energy, environment and development. London: Earthscan, 1996.

KERR, R. A. Rising global temperature rising uncertainty. Science, Washington, v. 292, p. 192-194, abr. 2001.

KONSTANTIN, Y. V. et al. Global Warming and Northern Hemisphere Sea Ice Extent. Science, Washington, v. 286, p. 1934 - 1937, dez. 1999.

LA ROVERE, E. L.; PINGUELLI ROSA, L.; RODRIGUES, A. P. Economia e tecnologia da energia. Rio de Janeiro: Marco Zero, 1985.

LASZLO, E. A strategy for the future: the systems approach to world order. New York: G. Brazziler, 1974.
MEADOWS, D. H. et al. Limites do crescimento. São Paulo: Perspectiva, 1978.

MINISTÉRIO DAS MINAS E ENERGIA. Balanço Energético Nacional. Brasília: MME, 2000.

MOTOYAMA, S. (Org.). Educação técnica e tecnológica em questão: 25 anos do CEETEPS. História vivida. São Paulo: Ed. Unesp, 1995.

NAISBITT, N.; NAISBITT, J. Will low tech replace high tech? Time, New York, v. 155, n. 25, p. 70-71, jun. 2000. Visions 21 special issue: The Future of Technology.

ODUM, E. P. Ecologia. Rio de Janeiro: Guanabara Koogan S. A., 1988.

POSTMAN, N. Tecnopólio: a rendição da cultura à tecnologia. São Paulo: Nobel, 1994.

SCHAFF, A. A sociedade informática: as consequências sociais da Segunda revolução industrial. São Paulo: Edusp, 1995.

VARGAS, M. Para uma filosofia da tecnologia. São Paulo: Alfa-Ômega, 1994.

VESTER, F. Neuland des Denkens. Munique: DTV, 1980.

VON BERTALANFFY, L. Teoria geral dos sistemas. Petrópolis: Vozes, 1973.

WIENER, N. Cybernetics. New York: John Wiley \& Sons Inc., 1948.

WORLD RESSOURCES. Time, New York, v. 157, n. 14, p. 20-26, abr. 2001. Special report: Global Warming. 